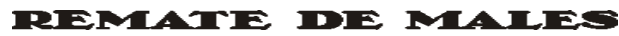

Campinas-SP, v. 38, n. 1, pp. 268-282, jan./jun. 2018

\title{
ESPAÇOS INTERSTICIAIS E IDENTITÁRIOS EM A ROSA CARAMELA E ROSALINDA, A NENHUMA, de Mia Couto
}

\author{
Antonio Cleonildo da Silva Costa ${ }^{1}$ \\ Maria Edileuza da Costa ${ }^{2}$
}

Resumo: A contemporaneidade tem apresentado diversidades culturais que exigem reflexão, sobretudo no âmbito da literatura. A representação do ser humano na ficção corrobora para a negociação estabelecida entre a autenticidade literária e a globalidade. Os espaços estão cada vez mais intersticiais porque se fazem notar a partir de uma busca híbrida de elementos identitários. Nesse contexto, o continente africano tem chamado a atenção a transnacionalidade de escritas pós-coloniais como a de Mia Couto, autor moçambicano. Nos contos A Rosa Caramela e Rosalinda, a nenhuma, a realidade sensível das personagens é delineada pela sutileza dos espaços externos e internos, os quais se dão em interstícios fragmentados por uma identidade em processo de (des)estabilização. Este artigo busca analisar como os espaços intersticiais se articulam enquanto representação fendida para formarem o que se pode chamar identidade.

Palavras-chave: estudos pós-coloniais; literatura africana de língua portuguesa; identidade cultural.

O Oceano Índico, através por exemplo de Moçambique, espalha escritas literárias que fazem pensar os espaços violados por questões coloniais ou existenciais. "A imagem da África é sempre acompanhada de epítetos negativos, fazendo sobressair o fascínio pela alteridade, ao

\footnotetext{
1 Professor de Língua Portuguesa e Literatura do Instituto Federal de Educação, Ciência e Tecnologia do Rio Grande do Norte - IFRN - e doutorando em Letras pela Universidade do Estado do Rio Grande do Norte: cleonildo.costa@ifrn.edu.br.

2 Professora de Literatura Brasileira do Departamento de Letras Vernáculas e do Programa de Pós-Graduação em Letras - PPGL, da Universidade do Estado do Rio Grande do Norte - UERN: edileuzacostauern@gmail.com.
} 
mesmo temida e atraente." (AUGEL, 2007, p. 130). Por isso, as literaturas africanas se estão difundindo além-fronteiras, porque não querem apenas reclamar um passado de dor ou exaltar uma cultura de glória, querem, sim, discutir os interstícios que se escondem por entre tais espaços. Estes, que não apenas negam um passado, mas reconfiguram um presente, são para Glissant (1981) a representação do diverso. O autor aduz:

O diverso que nãoéo caótico nem o estéril, significa o esforço do espírito humano em direção a uma relação transversal, sem transcendência universalista. O diverso tem necessidade da presença dos povos, não mais como objeto a sublimar, mas como projeto a pôr em relação. (GLISSANT, 1981, p. 190)

Não está em questão a menor ou a maior literatura, devido ao melhor ou ao pior povo, o que se pretende analisar é como, mediante o contexto supracitado, as representações identitárias vão se moldando e deixando fendas em sua configuração e nas relações num dado espaço-tempo.

A contemporaneidade com seus aspectos fluidos e fragmentados está recorrendo constantemente ao imaginário no espaço do neocolonialismo que "não pode ser mais o da ignorância ou da ingenuidade, nutrido por uma imaginação simplista dos dados oferecidos pela experiência imediata do autor, mas se afirmaria mais e mais como uma escritura sobre outra escritura" (SANTIAGO, 2000, p. 21). O próprio Santiago chama esse novo espaço de "entre-lugar" e, nesse sentido, ao se referir à literatura latino-americana, completa:

Entre o sacrifício e o jogo, entre a prisão e a transgressão, entre a submissão ao código e a agressão, entre a obediência e a rebelião, entre a assimilação e a expressão, - ali, neste lugar aparentemente vazio, seu templo e seu lugar de clandestinidade, ali, se realiza o ritual antropófago da literatura latino-americana. (SANTIAGO, 200o, p. 26)

O termo nasce de uma perspectiva não partidária e despretensiosa de qualquer tendência, o que não inviabiliza uma outra possibilidade de enxergar a identidade cultural. $O$ "entre-lugar, nutrido do que se pode definir como quase vazio, encontra-se no discurso do povo latino-americano que experimentou e ainda experimenta muitos extremismos ideológicos, econômicos e políticos de lados aparentemente imutáveis, pelas ideias defendidas. É como se o discurso dessa gente tratasse de uma descolonização do imaginário. 
Bhabha (1998) esclarece ainda mais acerca do termo, quando diz se tratar de uma subjetivação singular ou coletiva, pela qual são formuladas as representações que não podem cair nos extremismos. E acrescenta:

O que deve ser mapeado como um novo espaço internacional de realidades históricas descontínuas é, na verdade, o problema de identificar as passagens intersticiais e os processos de diferença cultural que estão inscritos no "entre-lugar”, na dissolução temporal que tece o texto global. (BHABHA, 1998, p. 298)

O que o autor acima defende é a possibilidade de sair do campo das ideias binárias e passar a compreender melhor os interstícios e as diferenças que estão acoplados às culturas, sem uma fixação temporal e obedecendo à perspectiva global. Todavia, a consciência ontológica que se deve criar está acima dos envolvidos, isso porque o que se deve levar em conta é o processo em trânsito, o vir a ser parcial e desenraizado da trama cultural.

Partindo da noção de entre-lugar, a qual se faz notar neste estudo, a literatura oportuniza entender melhor o termo na exposição proposta. Para nortear a pretensa análise, observar-se-á o que propõe Antônio Emílio Leite Couto ou simplesmente Mia Couto, autor moçambicano. Dentre as mais de trinta obras publicadas, o livro Cada homem é uma raça, uma coletânea de contos de 2013, será o condutor do presente trabalho, já que, a partir desse opúsculo, foram escolhidos para análise os contos $A$ Rosa Caramela e Rosalinda, a nenhuma.

Em A Rosa Caramela, a protagonista que rende o nome ao conto é uma corcunda solitária que se entretém a cuidar das estátuas de jardins. Abandonada no altar no dia do casamento, enlouquecera. A partir do surto, a enigmática mulher passou a procurar seu amor, encontrando as estátuas por consolação. Logo após, Rosa é presa por cuidar de uma estátua de colonizador. Ao sair da prisão, vai a um sepultamento e, despindo-se, joga as roupas dentro da cova de um defunto, questionando se poderia render livremente suas condolências àquele corpo morto. Ao final da narrativa, Rosa reencontra seu noivo.

No conto Rosalinda, a nenhuma, Rosalinda, mulher gorda e também solitária, é viúva de Jacinto, a quem visita constantemente no cemitério. Em certa ocasião, trava com o defunto um monólogo de prestação de contas da vida ruim que o marido lhe dera. Chama-o de sacana, traz à tona as surras que levara dele, relata as amantes que ele possuíra. Como se não bastassem as humilhações, seu cônjuge-defunto ainda está à espera de uma das amantes, que também sempre vinha visitá-lo no cemitério. 
A viúva, então, decide enganar o marido morto e a amante, trocando as inscrições da campa. Apesar do êxito na vingança, levando a outra de Jacinto a rezar para o defunto errado, Rosalinda se promove à "nenhuma".

As histórias narradas e propostas para análise nascem, a princípio, de um conflituoso espaço de gênero que se processa entre criador e criaturas. Quando o conflito acontece, não está em jogo a anulação das partes, mas a relação que surge da efusão entre elas, o que Bakhtin (2011) chama resposta axiológica às manifestações que as rodeiam. Nesse sentido, a construção da personagem se dá a partir da exibição de "muitos trejeitos, máscaras aleatórias, gestos falsos e atos inesperados em função das respostas volitivo-emocionais e dos caprichos de alma do autor" (BAKHTIN, 2011, p. 4).

Mia Couto, a partir de sua imaginação sensível, cria personagens femininas de inspiração moçambicana, por entendê-las melhor no contexto que o rodeia. Elas trazem em sua trajetória narrada as marcas de mulheres que são subalternizadas pela força masculina. A maneira de conduzir as narrativas leva o escritor moçambicano a ser um artista da envergadura proposta por Glissant (2005, p. 69):

\begin{abstract}
o artista é aquele que aproxima o imaginário do mundo; ora, as ideologias do mundo, as visões do mundo, as previsões, os castelos de areia começam a entrar em falência; e é preciso, portanto, começar a fazer emergir esse imaginário. E aí não se trata mais de sonhar o mundo, mas sim de penetrar nele.
\end{abstract}

As personagens de Mia Couto, aqui analisadas, representam a feminilidade posta em mais profunda reflexão frente a uma globalidade que existe também no espaço verossímil e transcultural. A inspiração contextual corrobora para o "imaginário da distância espacial - viver de algum modo além da fronteira de nossos tempos - dá relevo a diferenças sociais, temporais, que interrompem nossa noção conspiratória da contemporaneidade cultural" (BHABHA, 1998, p. 23).

As personagens em análise nos respectivos contos conduzem à tensão iminente, provinda da existência humana que desafia a encontrar uma relativização possível, não só de gênero, mas, sobretudo, da busca pelo eu; uma procura de si necessitária de um espaço ainda não existente em suas idealizações. "É nesse sentido que a fronteira existencial se torna o lugar a partir do qual algo começa a se fazer presente em um movimento não dissimilar ao da articulação ambulante, ambivalente, do além que venho traçando" (BHABHA, 1998, p. 24). 
Arraigada ao fluxo de movimento da busca por uma identidade intersticial, a pós-colonialidade insurge como uma força conflituosa, tal como o traço da modernidade tardia. Não é difícil perceber que a vida diária exige a construção do jogo dialético entre o local e o global, sendo que o indivíduo é forçado a fazer escolhas frente às diversas opções. A bem da verdade, existem influências padronizadas que precisam ser levadas em conta, mesmo que em um dado momento passem por filtros de conhecimentos especializados e estruturem uma autoidentidade.

Conhecer mais de perto Rosa Caramela e Rosalinda é arriscar-se por entre espaços existenciais locais e globais, os quais interligam uma variante de questões transnacionais e multiculturais. Fisicamente, ambas as protagonistas das narrativas, apesar de representarem tantas mulheres mundo afora, não atendem a um padrão exigido pela norma social. Elas são fruto de uma modernidade que produz diferença, exclusão e marginalização. Sobre Rosa Caramela, a narrativa aduz:

Dela se sabia quase pouco. Se conhecia assim, corcunda-marreca, desde menina. [...] Dela nem queríamos aceitar parecenças. Era a Rosa. Subtítulo: a Caramela. E ríamos. [...] A corcunda era a mistura das raças todas, seu corpo cruzava os muitos continentes. [...] A cara dela era linda, apesar. Excluída do corpo, era até de acender desejos. Mas se às arrecuas, lhe espreitassem inteira, logo se anulava tal lindeza. (COUTO, 2013, pp. 13-14)

De uma nítida contradição e de uma transnacionalidade evidente, Rosa Caramela parece existir por meio de uma negociação cultural, emergencial e paradoxal. Nesse sentido, "é na emergência dos interstícios - a sobreposição e o deslocamento de domínios da diferença - que as experiências intersubjetivas e coletivas de nação [nationness], o interesse comunitário ou o valor cultural são negociados" (BHABHA, 1998, p. 20). Nesse contexto de pressupostos culturais insólitos, a Caramela deixa rastros identitários que não se fixam, mas que se vão escorregando entre espaços e moldando uma fluidez que exclui o sistema de representação institucionalizado.

Não diferente, Rosalinda figura na narrativa entre o esvaziamento de si e as largas formas físicas que o seu corpo possui. Sua caracterização salta aos padrões consagrados, chegando ao ridículo por meio das formas avantajadas do seu físico. A narrativa esclarece:

Rosalinda era mulher resguardada, fornecida de assento. Senhora de muita poupa, carnes aquém e além roupa. Sofria de tanto volume que se sentava no próprio peso, superlativa. Já fora esbelta, dessas mulheres que explicam o 
amor Magreza sucedida em seus tempos. Pois que, desde que enviuvou, ela se desentreteu, esquecida de ser. (COUTO, 2013, p. 51)

A descrita viúva participa do dinamismo social que parece sugerir uma limitação padrão para as mulheres que podem explicar o amor. É como se apenas as não gordas pudessem saber desse sentimento. Além do mais, o processo intersticial de Rosalinda evidencia-se entre o avantajado corpo físico e a ausência de si. A personagem não se identifica consigo mesma e, por isso, tenta anular seu processo identitário ao afirmar ser a nenhuma.

Como relatado anteriormente, não se pode responsabilizar a complexidade do exposto a uma tradição cultural já autenticada, mas à emergência da comunidade concebida como projeto - ao mesmo tempo uma visão e uma construção - a qual "transporta para 'além' de si para poder retornar, com um espírito de revisão e reconstrução” (BHABHA, 1998, pp. 21-22). Na narrativa, a viuvez leva a personagem a se perder de si: "De passo miúdo, Rosalinda rumava entre as moradias subterrâneas, vacilando como se magoasse em sua própria sombra” (COUTO, 2013, p. 51).

Contudo, é no caos de si - o qual Glissant (2005) chama caosmundo, um espaço incalculável, sem pontos de referência normativos - que Rosalinda, ao se perder, se encontra. O que ela localiza não necessariamente é o convencional "feliz para sempre", mas é o essencial para ela, entender melhor a sua subjetividade. Em toda a narrativa, há uma premissa que precisa ser lembrada: quando há confiança, mesmo fragmentada e problemática, isso se mistura com as aceitações. E as ações, violentas ou não, vão se naturalizando. Nesse propósito, a esposa, por seu amor para com o marido, passa a aceitar naturalmente as ações machistas de quem "estava farto de ser marido, cansado de ser gente" (COUTO, 2013, p. 53).

O fato é que por longos anos, joelhos no chão e carícias na terra da campa do marido foi o ofício de Rosalinda. A narrativa ressalta: "Mas quem explica aquela saudade do sofrimento, o doce sabor das amargas lembranças?” (COUTO, 2013, p. 52). A viúva sente necessidade de conversar com o marido que amou em vida e, agora morto, ama com mais força. Quer desabafar: "Tu me amarraste a vida, me forneceste de porrada” (p. 52).

O desenvolvimento do conto chama a atenção para o entre-lugar em que a esposa se encontra. Ela é fiel mas traída ao mesmo tempo. Jamais 
deixou o marido sair desarrumado para se encontrar com as outras mulheres. Ademais, não permite fecharem os olhos do defunto porque segundo ela o "homem ainda está à espera de alguém" (COUTO, 2013, p. 53). Porém, "Depois dos améns, ela se descobriu apaixonada, por estreia na esteira da vida. Afinal, Jacinto, meu Jacinto. - Amor certo é mais que único" (p. 54).

A contemporaneidade, nesse contexto, faz pensar sobre o eu, ou mesmo sobre a extrapolação do que se pode chamar de primeira pessoa do discurso. Além do mais, chega-se ao "ponto em que já não se diz mais EU, mas ao ponto em que já não tem qualquer importância dizer ou não dizer EU. Não somos mais nós mesmos. [...] Fomos ajudados, aspirados, multiplicados" (DELEUZE; GUATTARI, 1995, p. 11). Entre o paradoxo do amor e as injúrias recebidas, Rosalinda escuta do seu marido palavras que direciona uma projeção do ser feminino no mínimo estranho, a ser pensado pela ótica tradicionalista para a construção do seu próprio eu:

- Teu nome, Rosalinda, são duas mentiras. Afinal, nem rosa, nem linda. Ela, em sorriso, comemorava. Suspirava em maré de alma, vaziando-se. No tardio presente, ela toda se dedicava a Jacinto, em subterrâneo namoro. A gorda se derramava como sumo de fruto tombado. (COUTO, 2013, p. 55)

Desse modo, o desfecho da narrativa corresponde a "um futuro intersticial que emerge no entremeio entre as exigências do passado e as necessidades do presente". (BHABHA, 1998, p. 301). Impelida, agora pela vingança, a viúva percebe Dorinha, a outra última do marido, que se põe a chorar. Assolada por um passado de traição e ladeada pelo choro de uma das amantes do cônjuge, Rosalinda decide: “- Em vida me enganaram. Agora, é meu troco” (COUTO, 2013, p. 57). Após trocar a inscrição da campa do marido, a esposa vê a amante do marido entregar o sentimento à cova errada. Com a vingança, Rosalinda tem sua identidade intersticial revelada: "E levaram a gorda mulher, aquela que foi viúva antes de ter sido esposa. Levaram-lhe para um lugar sombrio onde ela se converteu em ausência. Rosada, por fim, se promoveu a nenhuma" (p. 57).

As nuanças de identidade fendida da viúva são análogas às da corcunda Rosa Caramela. Esta última, além de subalternizada pelas condições de vida - pobre, magra, sem dignidade e abandonada pelo noivo no dia do casamento, apoia-se nas estátuas. "Ela queria curar as cicatrizes das pedras? Com maternal inclinação, consolava cada estátua: - Deixa, eu te limpo. Vou tirar esse sujo, é sujo deles. [...] E ela, frente aos 
estatuados, cantava de rouca e inumana voz: pedia-lhes que saíssem da pedra. Sobressonhava" (COUTO, 2013, p. 14). Além disso:

Rosa não tinha visitas, nunca recebeu remédio de alguma companhia. Ela se condizia sozinha, despovoada. Fez-se irmã das pedras, de tanto nelas se encostar. Paredes, chão, teto: só a pedra lhe dava tamanho. Rosa se pousava, com a leveza dos apaixonados, sobre os fios soalhos. A pedra, sua gêmea. (COUTO, 2013, p. 15)

A Caramela vive a sua totalidade-mundo. Seu universo é também a experiência desastrosa de insucessos. Sua deformidade física, o fato de ter sido abandonada pelo noivo e a relação íntima com as pedras, constroem lacunas, as quais, aglomeradas, contribuem para a identidade da corcunda-marreca. Sobre essa condição, Bhabha (1998, p. 80) complementa: "Viver a totalidade-mundo a partir do lugar que é nosso, é estabelecer relação e não consagrar a exclusão”.

As relações lacunares que passam a existir entre Rosa e as estátuas vai mais além, quando ela elege para si um monumento para chamar de preferido: "Era monumento de um colonial, nem o nome restava legível. Rosa desperdiçava as horas na contemplação do busto. Amor sem correspondência: o estatuado permanecia sempre distante, sem dignar atenção à corcovada" (COUTO, 2013, p. 16). A relação ser humano/estátua torna-se complexa devido à influência histórico-ideológica que há por traz da narrativa - a relação de subordinação de Moçambique mediante colonização.

Mesmo cientes de que, ao falar da relação colonizador/colonizado não se pode generalizar a discussão, é preciso notar que a passagem do conto em que Rosa Caramela é presa por cuidar da estátua do colono representa “a compreensão da difícil situação contemporânea vivida pelos países africanos que passaram por esse processo em fins do século XX. [...] Toda suspeição e ira contra o colonizador fora canalizada contra seus próprios irmãos" (CARDOSO, 2014, pp. 324-325). Isso quer dizer que moçambicanos que fossem, após a independência política, pegos corroborando de algum modo com os colonos, eram considerados traidores e/ou loucos. $\mathrm{Na}$ ficção, o conto tenta mostrar tal resquício histórico, constituindo-se de interstícios de uma identidade ainda amedrontada por um passado próximo. A seguinte passagem da narrativa esclarece:

Até que, um dia, nos chegou a notícia: a Rosa Caramela tinha sido presa. Seu único delito: venerar um colonialista. O chefe das milícias atribuiu a sentença: saudosismo do passado. A loucura da corcunda escondia outras, políticas razões. 
Assim falou o comandante. Não fora isso, que outro motivo teria ela para se opor, com violência e corpo, ao derrube da estátua? Sim, porque o monumento era um pé do passado rasteirando o presente. Urgia a circuncisão da estátua para respeito da nação. (COUTO, 2013, p. 18)A identificação da personagem com a estátua e o que logra com isso surge da socialização, intencional ou não, com determinado arcabouço físico que é focalizado. Augel (2007, p. 196) reforça: "A identidade espacial desenvolve-se [...] em um determinado espaço de um grupo social com normas, comportamentos e atitudes mais ou menos em comum". No entanto é, ademais, conjecturada por rastro/ resíduo o qual "não contribui para contemplar a totalidade, mas permite nos conceber o indizível dessa totalidade" (GLISSANT, 2005, p. 83).

Pelo exposto, seria mais difícil tentar chegar próximo à identidade de Rosa Caramela sem relacionar seus interstícios formadores pelo que não se diz, lançando mão dos agenciamentos apresentados por Deleuze e Guattari (1995) como processo rizomático. "Um rizoma não começa nem conclui, ele se encontra sempre no meio, entre as coisas, inter-ser” (p. 37).

Sem raízes que a prendam à família, à sociedade ou a qualquer instância que seja, a rizomática, ao ser presa, é lembrada pelo narrador-personagem: "Só então, na ausência dela, vimos o quanto ela compunha a nossa paisagem" (COUTO, 2013, p. 16). Na verdade Rosa é observada pelo filho de Juca, dono da casa do jardim onde estava a estátua da confusão, jovem que a vê apenas como objeto do seu jardim, assim como as estátuas o são. Já Juca, por sua vez, sempre muito preocupado em saber da corcunda, sente a ausência da cuidadora de monumentos estatuários. Em uma das conversas com o tio, o narrador, filho de Juca, relata que seu pai quer saber se Rosa já foi solta. O tio então lhe diz que a pobre mulher foi anistiada porque seu crime é a loucura. Conta ainda a cena do cemitério, quando do enterro de um enfermeiro que se suicidou por enforcamento, e a Caramela foi ver o féretro:

A Rosa por baixo das costas, toda de negro. Nem um corvo, Juca. Foi entrando, com modos de coveira, espreitando as sepulturas. Parecia escolher o buraco dela. No cemitério, você sabe, Juca, lá ninguém demorava a visitar as covas. Passamos depressa. Só essa corcunda, a gaja... - conta o resto - cortou meu pai. [...] a Rosa, ali, no meio de todos, começou a cantar. Com educado espanto, os presentes a fixaram. O padre mantinha a oração mas ninguém já lhe ouvia. Foi então que a marreca começou a despir. 
[...] a Rosa então rezou: - Leve essas roupas, Jawane, te vão fazer falta. Porque tu vais ser pedra, como os outros. Olhando os presentes, ela ergueu a voz, parecia maior que uma criatura: - E agora: posso gostar? [...] Hein? Deste morto posso gostar! Já não é dos tempos. Ou deste também sou proibida? (COUTO, 2013, pp. 22-23).

A presença e a voz de Rosa são subalternizadas como foram e ainda são as de tantas mulheres africanas. Apesar de Spivak (2010, p. 44) afirmar que "os oprimidos podem saber e falar por si mesmos", esses sujeitos marginalizados, na maioria das vezes, são retraídos em si mesmos e buscam espelhar-se nos outros sujeitos de quem percebem maior similaridade comportamental. Como Rosa não pode cantar para a estátua do colonialista, agora canta para um defunto que intencionalmente desejou ser pedra quando cometeu suicídio. Esse comportamento de Rosa faz com que reorganize seu pensamento e reestabeleça a voz que lhe foi calada com a prisão. Agora, diagnosticada como se louca fosse, pode externar seu mais profundo bradar e, diga-se de passagem, com sarcasmo e resignação.

A narrativa deixa claro o desprezo com que é tratada a marreca. A voz da África, e de tantos outros lugares, é ignorada pela representação religiosa dogmática com a qual está em embate a ínfima mulher. Mesmo despindo-se e expondo seu corpo deformado pela mazela física que lhe acomete para protestar seu direito de pensar, expondo sua vontade em meio aos que não lhe desejam ouvir, Rosa se sente maior do que uma criatura. Sem dogmas, sem rituais e sem roupas, a subalterna luta por seu direito de gostar; gostar de si por meio daquele que também se refugiou, despiu-se de uma realidade opressora. Glissant (2005, p. 84), sobre isso, reforça: "Esse é o desvio que não é nem fuga nem renúncia, mas a arte nova do desatamento do mundo".

Movediça, a fronteira representativa do que configura a existência de Rosa desata o mundo do ser quando esta é consolada pelo pai do narrador da história estudada:

\footnotetext{
- Não chora, Rosa. [...] - Sou eu, Rosa. Não lembra? [...] - Sou eu, Juca. O seu noivo, não lembra?

Aos poucos, Rosa Caramela se irrealizou. Ela nunca tanto existira, nenhuma estátua lhe merecera tantos olhos. [...]

- Vamos, Rosa. Pega suas coisas, vamos embora.

E foram-se os dois, noite adentro. (COUTO, 2013, p. 23)
} 
O desfecho do conto convoca algumas reflexões de entendimento rizomático repleto de interstícios identitários na configuração da protagonista. Primeiro, a inércia de Juca, descrita pelo próprio filho narrador da história - faz lembrar estátuas: “- Mano Juca, desarrasca lá uma maneira de viver. Meu pai nem respondia. Parecia mesmo que ele mais se tornava encostadiço, cúmplice da velha cadeira" (COUTO, 2013, p. 16). Caramela encontra na falta de atitude das estátuas e do defunto, rastros do que possuía seu grande amor Juca, que, apesar de agora casado, é quase estátua no seu lar e na relação com a família. A esposa é quem conduz tudo na casa do ex-noivo de Rosa.

Em segundo lugar, nasce uma premissa de interstício quando o próprio narrador, surpreso de ver o pai indo embora com uma outra aquela que era objeto entre outros objetos -, monta as peças inertes que um dia faltaram na história dos dois. Contudo, é no caos que a relação é retomada: "As mãos de meu pai se afundavam no cabelo da corcunda, pareciam gente, aquelas mãos pareciam gente se afogando" (COUTO, 2013, p. 23). Ademais, a aproximação dos dois dá-se no escuro e, ao irem embora, encaminham-se para a errância da noite. Juntos, objetos quase inanimados, vão viver sua história amorosa do passado, fato que deixa o próprio narrador perplexo. É seu pai, o sem atitude, a viver com a louca do jardim, ambos adquirindo o status de gente.

Ao que parece, sem querer alimentar os extremos das teorias binárias, a identidade de Rosalinda, a nenhuma, e a de Rosa Caramela têm a sua gênese no caos. A subalternidade intrínseca ao que lhes foi proporcionado física e existencialmente contribuiu para que essas mulheres criassem para si o que Deleuze e Guattari (1995, p. 9) chamaram de corpo sem órgãos. Para eles:

De todo modo você tem um (ou vários), não porque ele pré-exista ou seja dado inteiramente feito - mas de todo modo você faz um, não pode desejar sem fazê-lo - e ele espera por você, é um exercício, uma experimentação inevitável, já feita no momento em que você a compreende, não ainda efetuada se você ainda não a começou. Não é tranquilizador, porque você pode falhar. Ou às vezes pode ser aterrorizante, conduzi-lo à morte. Ele é não-desejo, mas também desejo. (DELEUZE; GUATTARI, 1995, p. 9)

Inacabadas do começo ao fim de suas trajetórias narrativas, a gorda é levada a um lugar sombrio e a corcunda envereda noite adentro com seu estranho amor. Daí fica evidente o nomadismo e as incompletudes da existência de ambas as mulheres. Suas desordens e inutilidades fazem 
intersecção com seus desejos e sonhos. Margeadas por preconceito, dogmas, amálgamas socioculturais e ranços ideológicos, elas se esvaziam e, com isso, criam agenciamentos. Ao fazê-lo, escolhem o insólito jeito de se resolver, afinal são desterritorializadas das marcas comportamentais da vida.

A verossímil perspectiva social vislumbrada entre a história e a literatura revela uma realidade intervalar, cujos sujeitos, como lembra Bhabha (1998), inscrevem-se em uma existência fronteiriça. A estranheza do enquadramento cria uma singular experiência que acaba ganhando horizontes peculiares nas linhas de fuga. Nesse espaço insólito, o neocolonialismo, mesmo que inconscientemente, traz à tona ranços de um projeto dominador/dominado. Augel (2007, p. 146) comunga com o exposto ao afirmar:

É mantida a dependência [...] no plano do subconsciente, das populações exploradas, submetidas a um sujeito psicológico e mental que os leva a querer satisfazer suas necessidades tanto culturais quanto materiais a partir dos bens e valores etiquetados como imprescindíveis por parte desse mundo primeiro e perfeito.

Apesar do entendimento de que as identidades intersticiais contemporâneas estão cada dia mais agenciadas por entrelugares, as marcas histórico-sociais que cravaram a ideia de dependência ou de normatividade, ordenadas por um mundo "perfeito", ainda sondam os dias presentes. Isso é possível de ser entendido quando se observa a motivação das narrativas, uma vez que as duas personagens-protagonistas dos respectivos contos analisados vislumbram a ordem social, mas são impelidas ao seu avesso. Por meio da desordem e de um não se enquadrar nas exigentes premissas sociais, elas se encontram enquanto sujeitos de sua própria história, de seu próprio mundo.

Rosa Caramela, por um lado, deseja casar na igreja, vestida de noiva e constituir uma família fundada pelo que prescreve a norma vigente da ordem que o mundo escolheu seguir. No entanto, com os desvios de seu percurso solitário, sua errância a leva a um lugar intersticial de busca que, provocado pela vigente ordem, não a faz satisfeita, colaborando para o caótico e para o substancial jeito identitário de ser. Na linha tênue dos sonhos adquiridos por meio do consagrado meio, e na urgência do encontro com a própria representação de si, Rosa Caramela consegue fundir extremos na sua peculiar vida. 
Por outro lado, enquanto muitos sujeitos vivem à procura de uma totalidade existencial, pautada na busca pela felicidade, Rosalinda se promove à nenhuma. A viúva também deseja implicitamente ter um marido vivo só para ela, mas em vida ele era de outras mulheres. Já morto, aparentemente sem utilidade alguma, Jacinto passa a ser a alegria do reencontro, do desabafo, da vingança e do amor. Nesse entremeio, nem rosa nem linda, só a mulher que encontra seu título de ausência, de anulação e de esvaziamento de si por meio de terapias frente a uma campa, de um marido-defunto só dela; de um luto particular; de um recolhimento silencioso também único.

Finalmente, as identidades intersticiais se revelam à medida que a literatura vai cumprindo sua função de fazer fronteiras com a realidade concreta. Dessa fronteira nasce entrelugares que estão muito além de um fim normativo. As histórias de Rosa Caramela e de Rosalinda, a nenhuma promovem uma leitura literária audaciosa e humanizadora que, para Bhabha (2010, p. 29), "é a capacidade da arte de revelar o limite atenuado e quase impossível de ser alcançado, em que a aura e a ágora se sobrepõem, a habilidade da arte de encontrar uma linguagem para os altos horizontes da própria humanidade". E isso vem se efetivando através da arte de um moçambicano, já mencionado anteriormente, que empresta ao mundo uma globalidade que vai muito além do continente africano. A globalidade exposta aqui, portanto, permite que este trabalho provoque outros pressupostos analíticos e humanizadores.

Muito ainda há de estudos a serem desenvolvidos acerca de uma literatura subscrita na região do Índico e que, pesarosamente, é tratada como menor, ínfima. Provou-se, aqui, sem entrar no mérito da negritude, que as literaturas dos países de população predominantemente negra, como é o caso de Moçambique, entrega ao mundo leitor arte literária de cunho provocativo. A literatura, nesse contexto, não está sendo feita apenas para questionar etnia, mas para cumprir seu papel de colocar em questão o ser humano e suas peculiaridades. As Rosas Caramelas e as Rosalindas são transnacionais, iguais e diferentes no espaço-tempo em que são reconhecidas. Intersticiais, portanto, pois os sujeitos que desejarem podem com elas se identificar, no sentido de apoiar ou criticar seus comportamentos. 


\title{
INTESTITIAL AND IDENTITY SPACES IN A ROSA CARAMELA E ROSALINDA, A NENHUMA, BY MIA COUTO
}

\begin{abstract}
The contemporary has presented cultural diversities that exclaim reflection, especially in the literature. The representation of the human in the fiction corroborates to the negotiation established between the literary authenticity and the globality. The spaces are each time more interstitial because are perceived from a hybrid search of identity elements. In this context, Africa has called attention to transnationality of postcolonial writings as by Mia Couto, Mozambican author. In the tales A Rosa Caramela e Rosalinda, a nenhuma, the sensitive reality of the characters is outlined by subtlety of this externs and interns spaces, which are in fragmented interstitial by an identity in process of (de) stabilization. This article seeks to analyze as the interstitial spaces articulate in this narratives while split representation to format what can be called identity.

Keywords: postcolonial studies; african literature of portuguese language; cultural identity.
\end{abstract}

\section{REFERÊNCIAS}

AUGEL, Moema Parente. O desafio do escombro: nação, identidades e pós-colonialismo na literatura da Guiné-Bissau. Rio de Janeiro: Garamond, 2007.

BAKHTIN, Mikhail. Estética da criação verbal. 6. ed. São Paulo: WMF Martins Fontes, 2011.

BHABHA, Homi K. O local da cultura. Trad. Myriam Ávila; Eliana Lourenço de Lima Reis; Gláucia Renate Gonçalves. Belo Horizonte: Editora UFMG, 1998.

BHABHA, Homi K. O bazar global e o clube dos cavalheiros ingleses: textos selecionados de Homi Bhabha. F. Coutinho (Org.). Trad. Tereza Dias Carneiro. Rio de Janeiro: Rocco, 2010.

CARDOSO, Sebastião Marques. Cosmologia literária da violência: uma leitura sobre a condição pós-colonial africana. Crítica Cultural. Critic, Palhoça, SC, v. 9, n. 2, jul.dez., 2014, pp. 323-333.

COUTO, Mia. Cada homem é uma raça: contos. 1. ed. São Paulo: Companhia das Letras, 2013.

DELEUZE, Gilles; GUATTARI, Félix. Mil platôs: capitalismo e esquizofrenia. Trad. Aurélio Guerra Neto e Celia Pinto Costa. São Paulo: Ed. 34, 1995.

GLISSANT, Édouard. Le discours antillas. Trad. Normélia Parise. Paris: Seuils, 1981, pp. 190-201. (Lê Même et le Divers)

GLISSANT, Édouard. Introdução a uma poética da diversidade. Trad. Enilce Albergaria Rocha. Juiz de Fora: Editora UFJF, 2005. 
Espaços intersticiais e identitários em A rosa caramela e Rosalinda - 282

SANTIAGO, Silviano. Uma literatura dos trópicos: ensaios sobre dependência cultural. 2. ed. Rio de Janeiro: Rocco, 2000.

SPIVAK, Gayatri Chakravorty. Pode o subalterno falar? Trad. Sandra Regina Goulart Almeida; Marcos Pereira Feitosa; André Pereira Feitosa. Belo Horizonte: Editora UFMG, 2010. 